\title{
NEW PIEZO OSCILLATIONS WITH QUARTZ CYLINDERS CUT ALONG THE OPTICAL AXIS
}

\author{
By August Hund and R. B. Wright
}

\section{ABSTRACT}

It is shown that oscillations of a new type can be produced, using a quartz cylinder cut along the optical axis. Some of the electrode mountings used were suggested by Röntgen's experimental work and the more recent work of Tawil. In order to produce these oscillations it was necessary to use new adaptations of regenerative circuits as the driving circuit.

These oscillations were studied experimentally through the medium of glow discharge patterns, a phemomenon of ionization produced by the quartz cylinder oscillating in a few millimeters of helium. They were studied theoretically by comparing the observed frequencies of oscillation with the computed values for the three different types or modes of vibration. Both studies indicate that these oscillations are of a true piezo-electric character.

\section{CONTENTS}

Page

383

384

385

386

386

389

390

391

394

\section{INTRODUCTION}

In relation to crystalline quartz cylinders cut along the optical axis, E. P. Tawil ${ }^{1}$ describes a new phenomenon, which he states to be different from piezo-electric phenomena, and suggests that it be called "strepho-electricity." In the description it is shown how opposite electrical charges appear, respectively, on the cylindrical surface and the ends when such a cylinder is subjected to a torsion about its cylindrical (and optical) axis. The charges thus produced appear to be proportional to the variation of the torsional strain. Moreover, the polarity of these charges reverses when the direction of torsion is reversed, and, in addition, the polarity is dependent upon the optical structure of the quartz, or, specifically, upon the optical rotation thereof.

In 1890, W. C. Röntgen, ${ }^{2}$ experimenting with static torsional forces on this same type of quartz cylinder cut along the optical axis, found that a twist about this axis produces charges of opposite polarity in consecutive quadrants around the cylinder, as is indicated in Figure 1. A, B, C, D, E, and F denote points of neutrality around the cylinder (which is assumed perpendicular to the plane of the paper) when ordinary piezo-electric effects occur, whereas $\alpha, \beta, \gamma$, and $\delta$ mark such points of zero surface charge on the envelope when tor-

1 Nouveau mode de developpement d'électricité par torsion dans les cristaux de quartz. (New method of producing electricity by torsion on quartz crystals.) Comptes Rendus, 187, pp. 1042-1044; Dec. 3, 1928.

Wied, Ann, d. Physik, 39, p. 16; 1890, 
sional stresses are acting. Those polarities indicated in the figure within two concentric circles denote the charges developed by torsional stress, while those within the single circles refer to ordinary piezo-electric polarizations. A result such as indicated in this figure does not seem to be correct for quartz, considering its three piezoelectric axes, which should ordinarily lead one to expect six alternate charges around the cylinder. Röntgen himself doubted the outcome of his experiment somewhat and repeated it with the same result; a result which would be in direct contradiction to W. Voigt's theory if the cylinders used were accurately oriented. ${ }^{3}$

Both the above experiments dealt with static torsional forces. One of the purposes of this paper is to show that dynamic torsional forces can produce electric effects, and vice versa. A second purpose is the

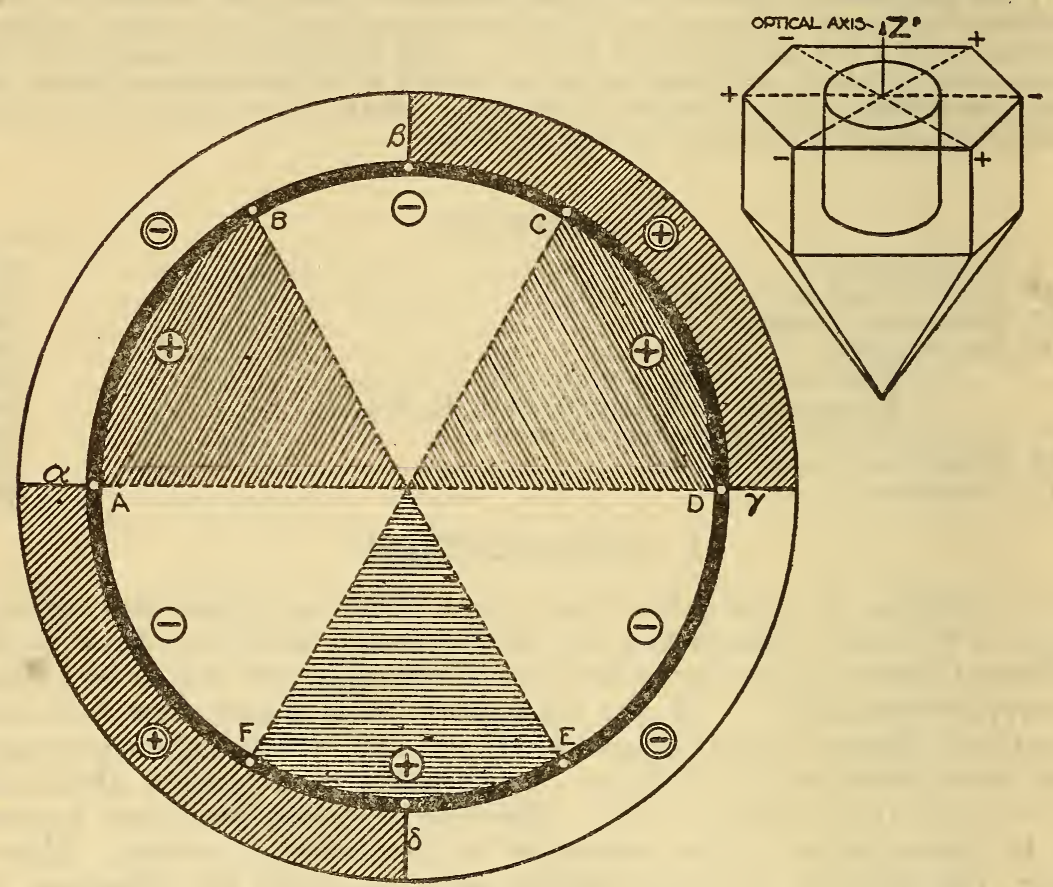

FigURE 1.-Charges on quartz cylinder (both when normal and when torsional strains exist)

demonstration of new oscillations produced with crystals cut along the optical axis, which oscillations, incidentally, may be explained theoretically without conflicting with Voigt's theory. A third purpose of this paper is to show that these oscillations embody true piezoelectric action.

\section{CIRCUITS USED IN THE EXPERIMENTS}

Ordinary circuits ${ }^{4}$ can not be used for producing oscillations of this type. This is due, no doubt, partially to the fact that the

3 W. Voigt, Lehrbuch der Kristallphysik, pp. 879-891; see conclusions on p. 891.

4 In which the piezo-electric element is connected either between the grid and the filament, or between the grid and the plate, and in which a condenser in parallel with a coil is employed in the anode branch. (For details, see Proc. I. R. E., 14, pp. 447-469; August, 1926.) 
modulus $\delta_{14}$ which has the value of only $+1.45 \times 10^{-8}$ cgs electrostatic units, is operative in the case of torsional oscillations, whereas the modulus responsible for the more usual "Curie cut" oscillations has the value $\delta_{11}=-6.45 \times 10^{-8}$ cgs electrostatic units. ${ }^{5}$ It was therefore necessary to resort to circuits which are so regenerative that they are on the verge of self-oscillation. The arrangements $a, b, c$, and $d$ of Figure 2 were found to work satisfactorily, In the systems $a$ and $b$ a small condenser $\mathrm{C}_{o}$ is employed for adjusting the feed-back. In the system $d$ a small condenser may or may not be used across the piezo-electric element.

\section{ELECTRODE MOUNTINGS}

The experiments by Röntgen as well as the recent investigation by Tawil suggest two mountings, shown in Figure $3, A$ and $B$, respectively. These will be referred to throughout the paper as mountings $A$ and $B$. It is seen that mounting A consists of four electrodes placed around the cylinder, of which
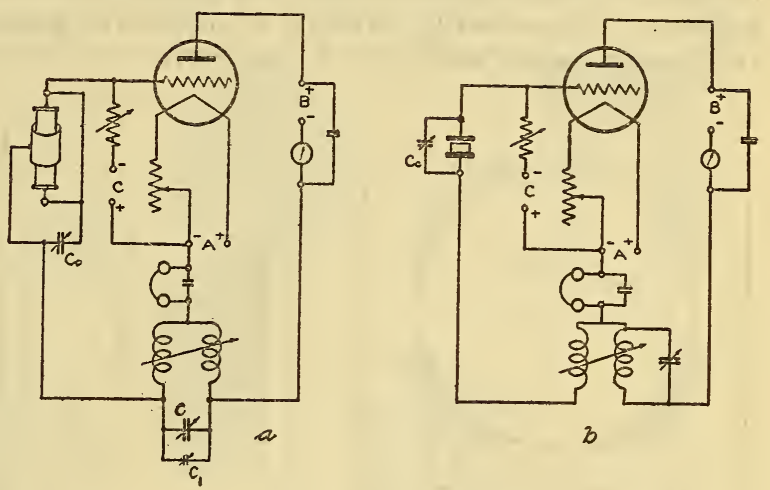

b
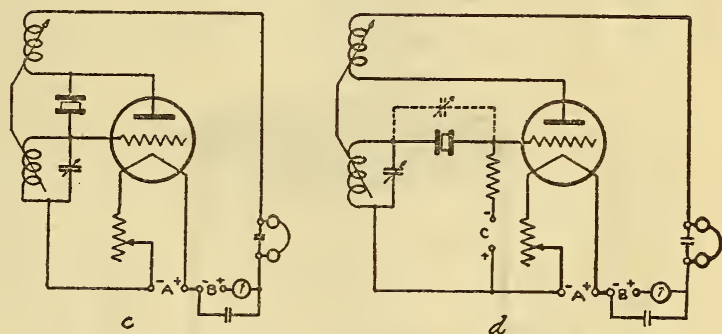

FIGURE 2.-Driving circuits for oscillations

alternate ones are of the same polarity, while for mounting $B$ a cylindrical electrode acts with respect to the two end electrodes which are in parallel.

Other mountings with which oscillations were obtained are indicated in Figures 4 and 23. Mounting $\mathrm{C}$ consists of three electrodes properly located with respect to the three piezo-electric axes, connected in parallel to form one terminal, while the other terminal is formed by the two end disks in parallel.

Mounting $\mathrm{D}$ consists of two sets of three electrodes each. One set connects to the upper end disk, and the other to the lower disk. The electrodes of the upper set, like those of the lower set, are spaced $120^{\circ}$ apart around the cylinder, one set having an angular displacement of $60^{\circ}$ with respect to the other.

$\checkmark$ Here each of the three different types or modes of vibration, including both their respective fundamentals and modes of higher frequency, must be distinguished from the other two. The three different types or modes of vibration referred to are: (1) longitudinal vibration, (2) transverse or bending vibration, and (3) torsional vibrations. This paper describes the first-known successful attempt to produce torsional vibrations along the optical axis, 
Mounting $\mathrm{E}$ consists of six metal strips around the cylinder, alternate ones being interconnected. No end disks were used in this case. This electrode system corresponds closely to the piezo-electric structure of the cylinder.

Mounting $F$ consists of three rings around the cylinder, the two end ones being opposite in polarity to the central one.

Mounting G (see fig. 23) consists of six strips around the upper portion of the cylinder and six strips around the lower portion, adjacent strips being always of opposite polarity. Mountings of this nature were made by fixing strips to the inside of a glass tube

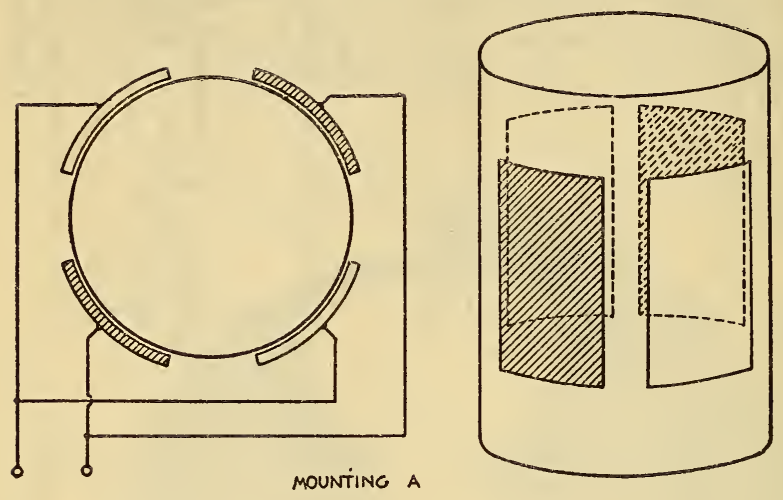
which was placed around the quartz cylinder.

\section{EXPERI- MENTAL}

\section{EXPERIMENTS WITH MOUNT. ING B}

For studying different modes of vibration, either the dust method by Kundt, ${ }^{6}$ or the glow discharge method used by

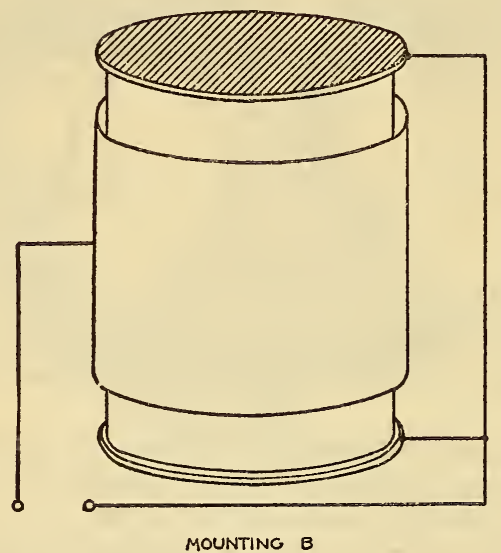

FIGURE 3.-Electrode mountings for new ocillations Giebe and Scheibe ${ }^{7}$ are convenient means. Since the glow-discharge method has advantages over Kundt's procedure, it was used.

Glow discharges under a gas pressure of several millimeters of mercury were produced in neon, in helium, in a mixture of both, and in nitrogen, but most of the photographs shown here were of the quartz cylinder oscillating in helium.

When using mounting $B$ the upper disk was omitted in order that the end pattern might be observed. This mounting, as well as

6 A. Kundt, Über eine einfache Methode zur Untersuchung der Thermo-Elektricität und Piezo-Elek tricität der Krystalle. (On a simple method for the investigation of thermoelectricity and piezoelectricity of crystals.) Berlin Akademie, 16, p. 421; 1883.

$7 \mathrm{E}$. Giebe and A. Scheibe, Sichtbarmachung von hochfrequenten Longitudinalschwingungen piezoelektricher Kristallstäbe. (Luminous effects of high frequency longitudinal vibrations of piezo-electric crystals.) Z. f. Phys., 33, p. 335, 1925; and Elektrotechnische Nachrichtechnik, 8, pp. 65-82, February, 1928. 
all others, consisted of electrodes of aluminum. In this way the sputtering of the crystal was avoided. The air gap between the crystal and the cylindrical electrode of mounting B was about $1 \mathrm{~mm}$.

Figure 5 shows a cylinder in oscillation, with discharge effects along the optical axis. On pursuing the study of this type of discharge, it was found that for a higher gas pressure (and, incidentally, with a cylindrical cut crystal whose height was slightly less than the one shown in fig. 5) a small spherical discharge appeared, rising some distance above the crystal as shown in Figure 6. The crystal oscillation for this case produced a steady alternating current of $118 \mathrm{kc}$. With the same cylinder an axial glow, similar to that shown in Figure 5, appeared at a frequency of $179 \mathrm{kc}$. By properly adjusting the voltage of the oscillation by means of the feed-back, however, the various patterns, $a, b, c$, and $d$ shown in Figure 7 could be produced. As may be readily understood by a comparison of the photographs with the diagrams which accompany them, it was difficult to get faithful photographic reproductions. In many cases the patterns as they appeared to the eye, consisted of designs beautiful in their detail. Four of these cases are to be found in Figure 7. The pattern shown in Figure $7(a)$ looked like a small equilateral triangle with a circular glow inside. The dotted portions indicate discharges from the pattern over the surface toward the cylindrical electrode. In Figure 7 (b) only a triangular glow appeared, whereas in $(c)$ a triangular glow appeared in the center with three circular
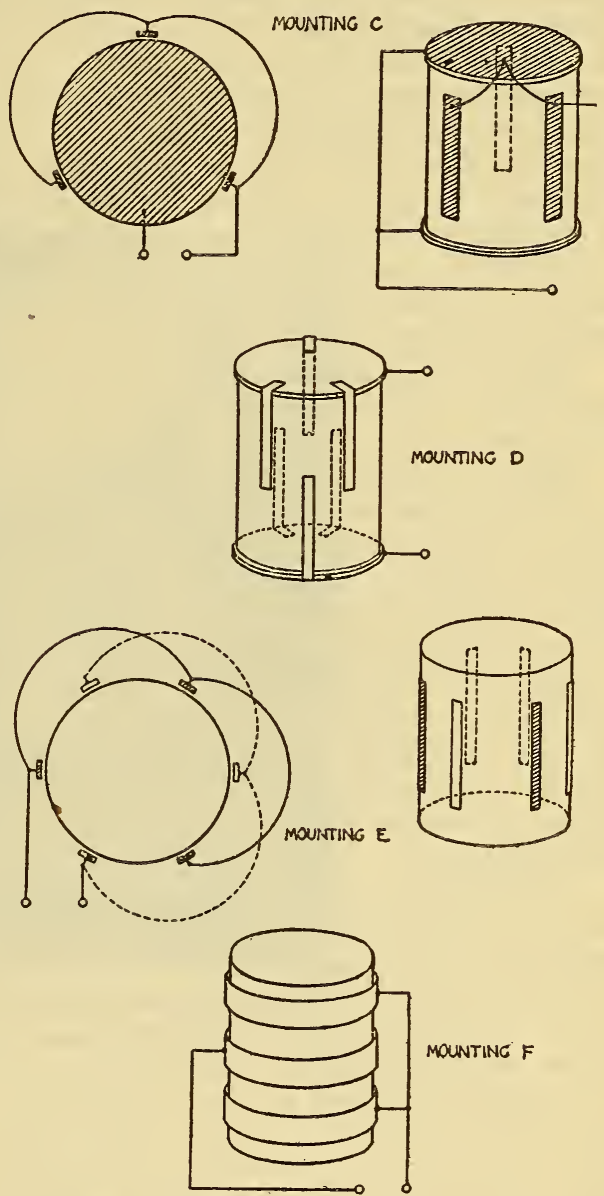

FigdRE 4.-Other electrode mountings for new oscillations glows, spaced $120^{\circ}$ around the end face of the cylinder. For these discharge patterns and all the others, the dotted lines indicate discharge between surface-charge patterns or between surface-charge patterns and the electrode or electrodes around the cylinder.

Generally speaking, the $179 \mathrm{kc}$ oscillation (fig. 7) was always characterized by a triangular pattern, whereas to the $118 \mathrm{kc}$ oscillation of Figure 6 there always corresponded a circular pattern at the center. 
The same cylinder oscillated also at $288 \mathrm{kc}$, with a discharge pattern as shown in Figure 8 . It will be noted that two diametrically located large circular glow discharges were accompanied by four small discharge points $a, b, c$, and $d$ spaced evenly around the envelope of the cylinder, completing in a way the hexagonal formation which one would expect on account of the three piezo-electric axes.

Figure $9(a)$ shows three circular surface discharges on the top of the crystal, which were located at the corners of an equilateral triangle. There were also six circular surface discharges around the cylinder which indicate again the hexagonal structure of the quartz. The discharges from the corners of the hexagon to those of the triangle probably occur alternately, since points $b$ and $c$, as shown in the figure, must be of opposite polarity. In other words, it is very probable that the discharge from $a$ to $b$ occurs during one half cycle and the discharge from $a$ to $c$ during the succeeding one. The patterns shown in Figure $9(a)$ and $(b)$ were obtained with the same cylinder oscillating at the same frequency in helium. The difference in the patterns is due to a difference in the pressure of the helium gas, a lower pressure being used in the case of Figure $9(b)$.

Figure 10 shows the case of a $301 \mathrm{kc}$ oscillation. The piezo-electric symmetry of the cylinder can in this case be interpreted only from the three circular surface discharges on the top face.

Figure 11 shows a pattern for which the circular surface discharges on the top face were at the corners of two equilateral triangles. The corners of the smaller triangle were the mid-points of the sides of the larger triangle. In addition, around the cylindrical envelope, near the top face, three more surface discharges were visible. They indicate again part of the hexagonal structure of the quartz.

Figure 12 indicates most strikingly the piezo-electric nature of this class of oscillations. The circular surface discharges accompanying this frequency of oscillation appear around the envelope near the top face, while for the case of the $296 \mathrm{kc}$ oscillation they are to be found, as shown in Figure 13, on the top face, somewhat inside the circumference.

At this point it was deemed important to find out whether those circular surface discharges which appear on top, or those appearing around the envelope, mark the three piezo-electric axes of the crystal. To determine this it was first necessary to locate these axes. With this end in view the quartz cylinder was suspended between two parallel plates to which $20 \mathrm{kv}$ (taken from a d. c. source) was applied. In an electrostatic field of this strength the crystal readily turned itself into such a position that one of the three piezo-electric axes was along the lines of force; that is, perpendicular to the plates. From this test it was found that the glow discharge of the $331 \mathrm{kc}$ oscillation (fig. 12) marked exactly the piezo-electric axes of the cylinder, while the six surface discharges of Figure 13 appeared halfway between these axes, as is indicated in the figure.

Another interesting glow discharge occurred with a $262 \mathrm{kc}$ oscillation, shown in Figure 14. Again we find six discharge spots on the top face which produced six space discharges, which in turn ran together, forming a discharge ring somewhat above the cylinder. From the ring-shaped discharge six space discharges ran radially outward and then down the cylinder toward the cylindrical metal electrode. 
B. S. Journal of Research, RP156

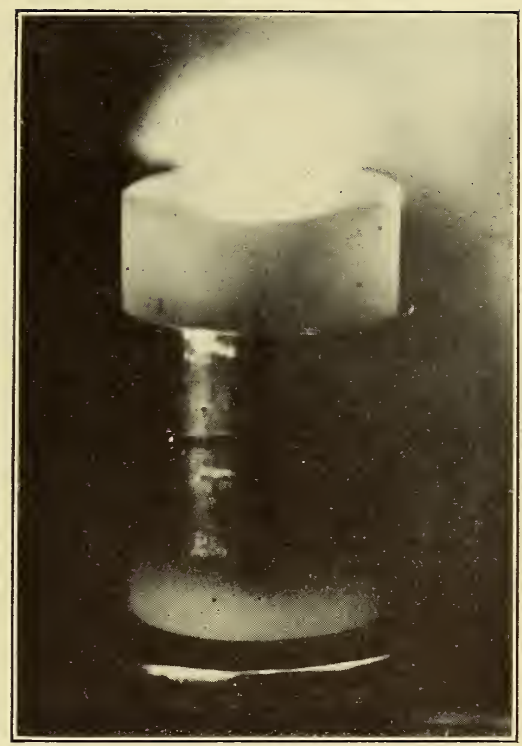

Figure 5.-186 kc, mounting $B$, height $38.3 \mathrm{~mm}$, diameter 24.715 $\mathrm{mm}$ 
B. S. Journal of Research, RPI56
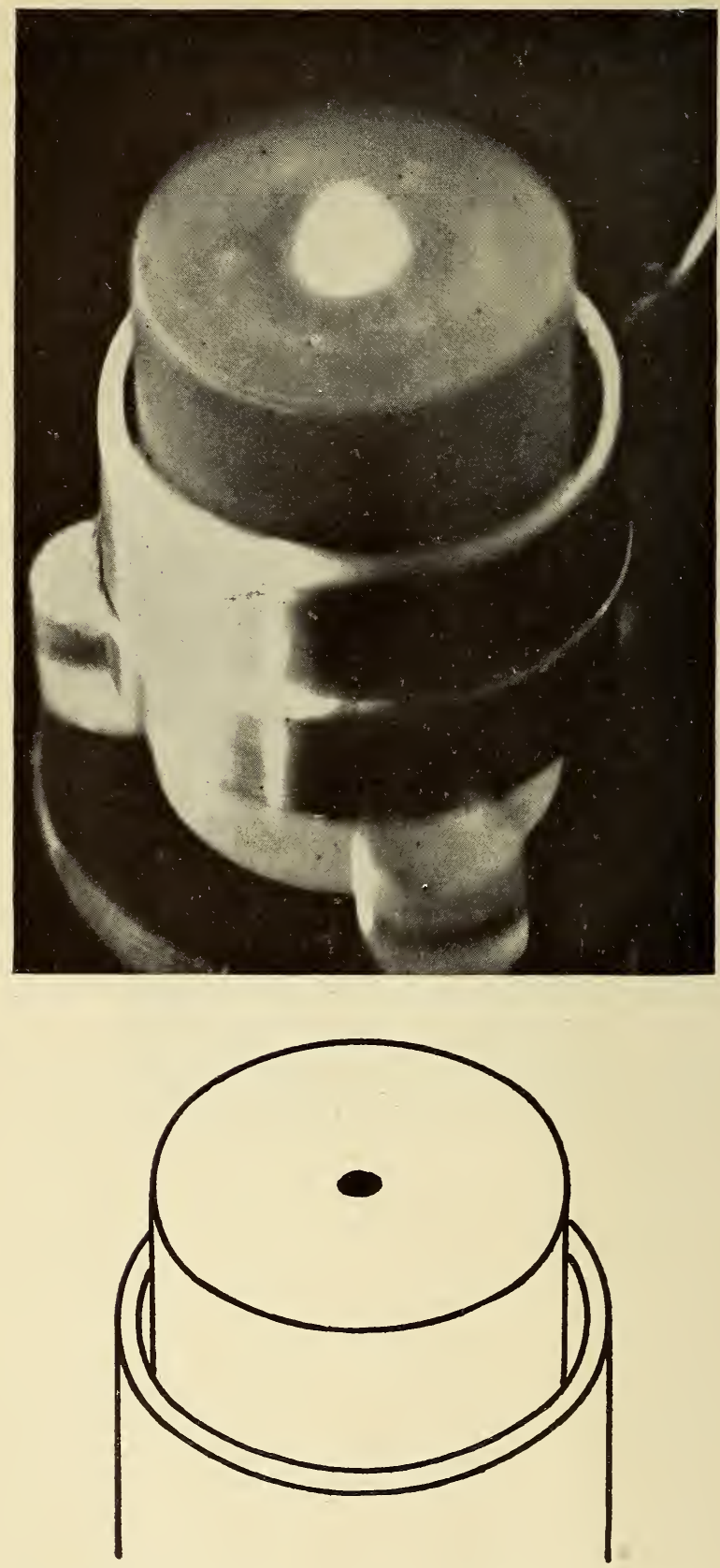

Figure 6.-118 kc, mounting $B$, height $36.67 \mathrm{~mm}$, diameter $24.715 \mathrm{~mm}$ 

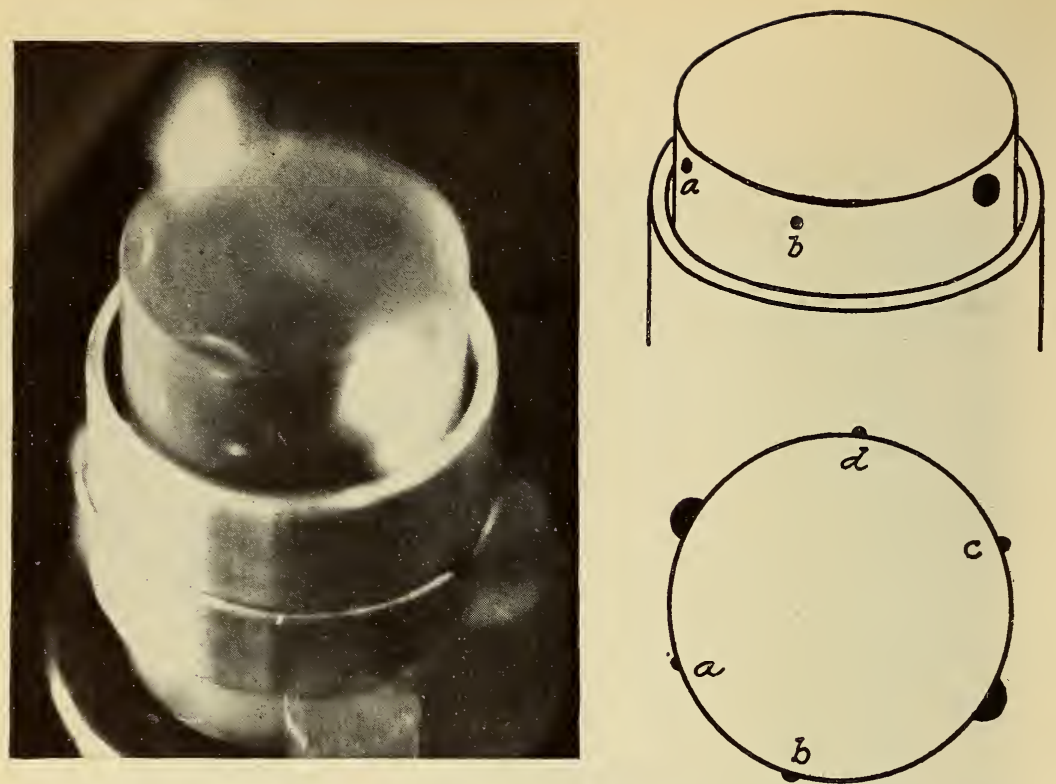

Figure 8.-288 kc, mounting $B$, height $36.67 \mathrm{~mm}$, diameter $24.715 \mathrm{~mm}$
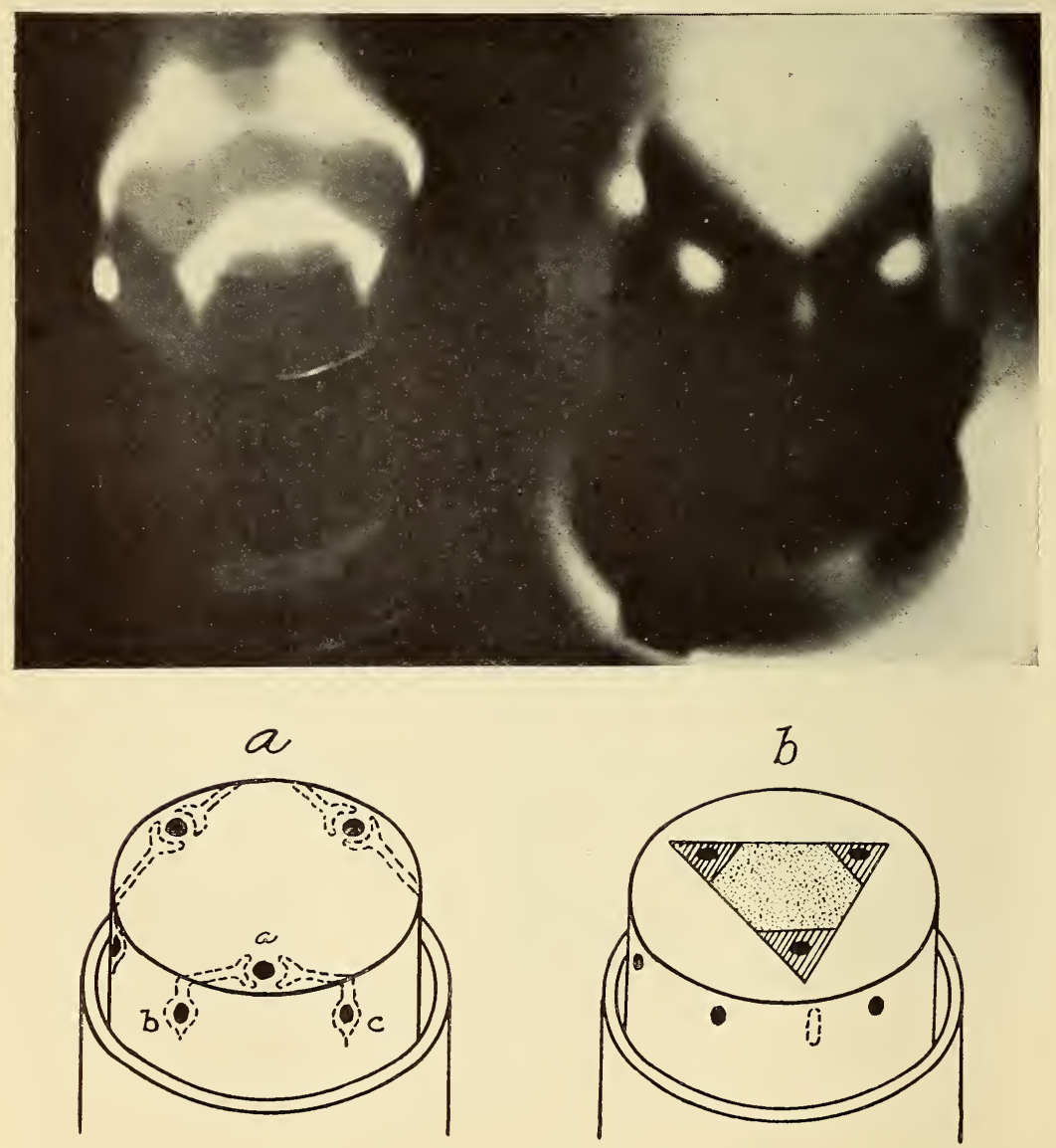

FigURE 9.-269 $\mathrm{kc}$, mounting $B$, height $38.3 \mathrm{~mm}$, diameter $24.715 \mathrm{~mm}$ 


\section{B. S. Journal of Research, RP156}
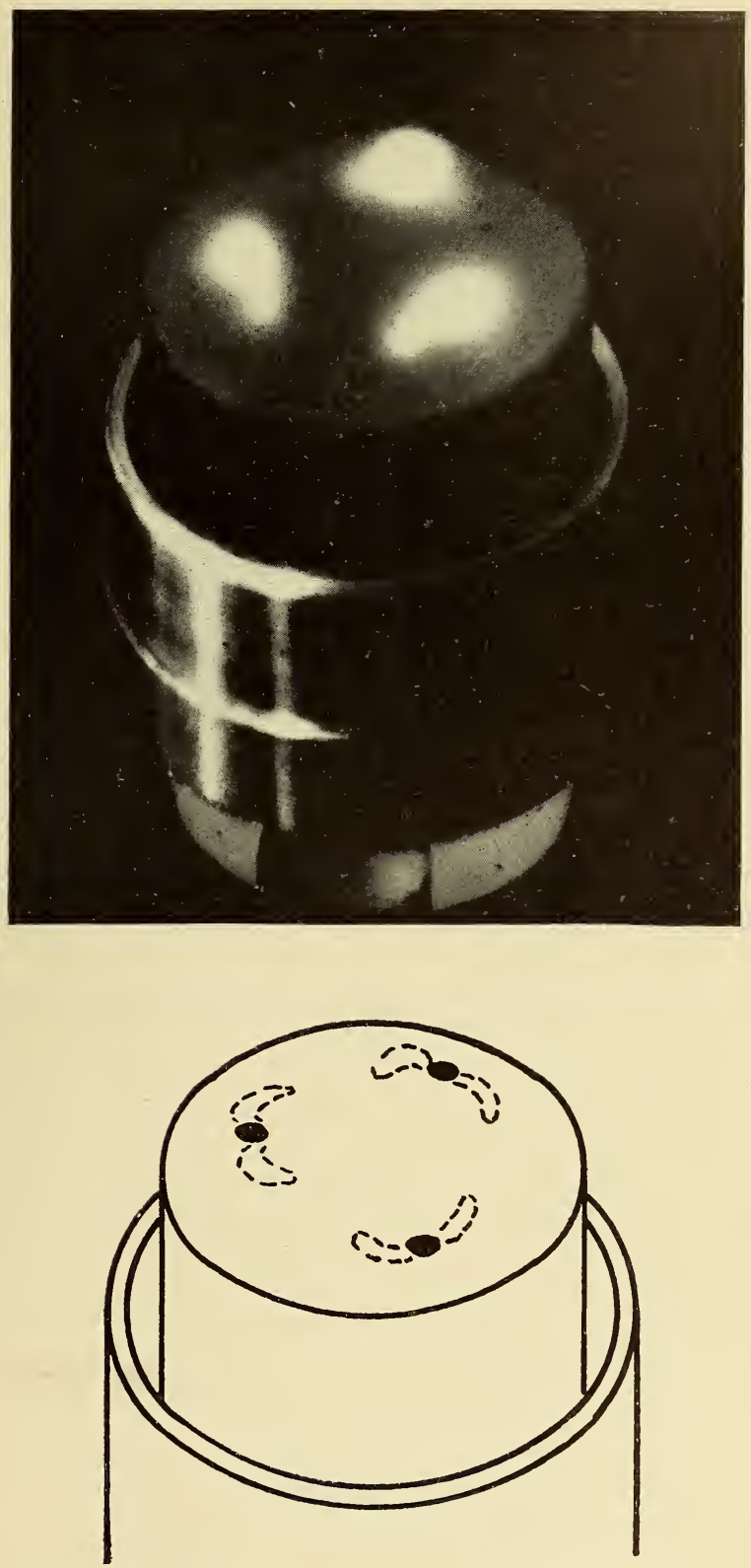

Figure 10.-301 kc, mounting $B$, height $36.67 \mathrm{~mm}$, diameter $24.715 \mathrm{~mm}$ 

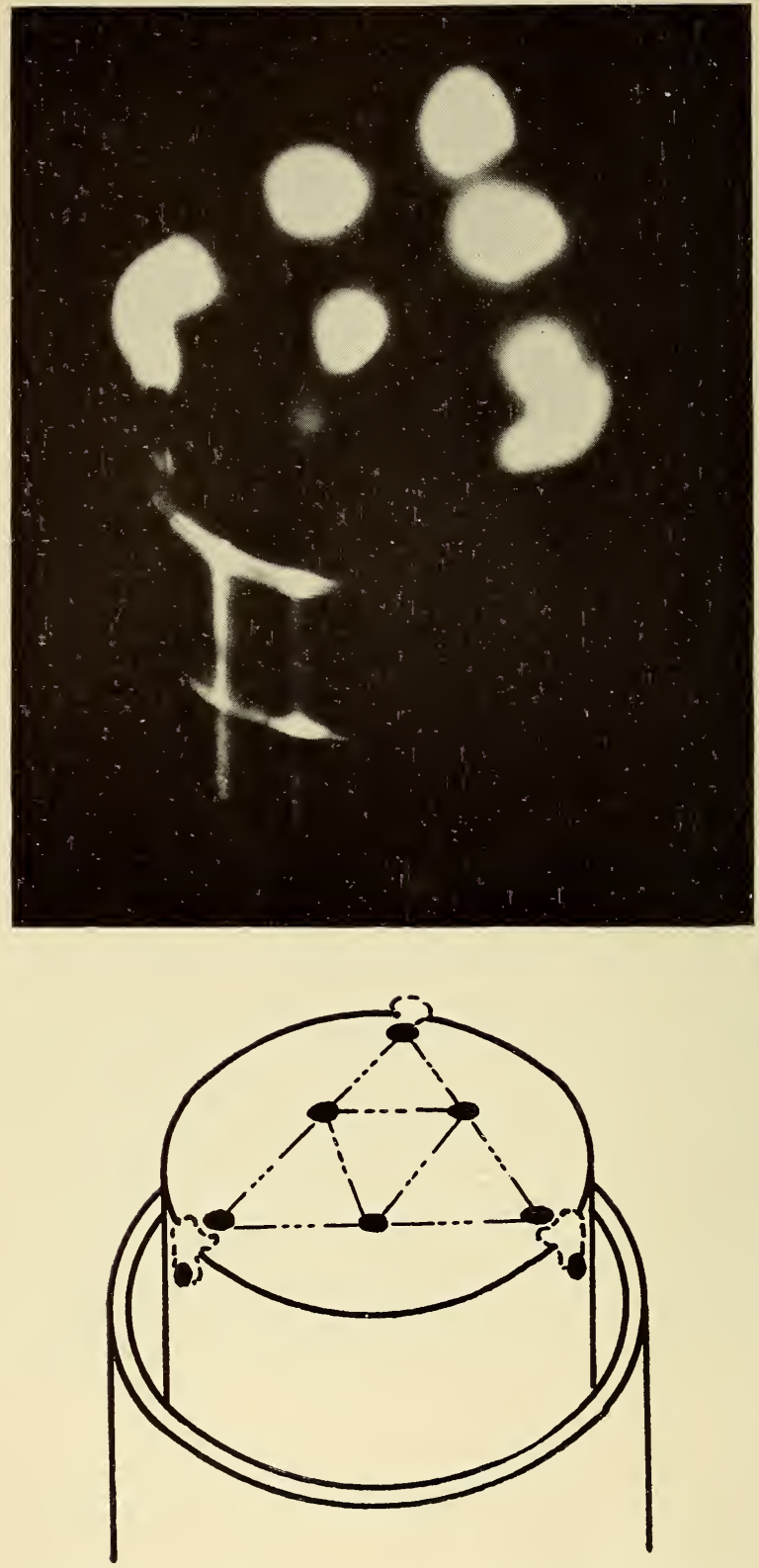

FIGURE 11.-394 kc, mounting $B$, height $36.67 \mathrm{~mm}$, diameter $24.715 \mathrm{~mm}$ 


\section{B. S. Journal of Research, RP156}
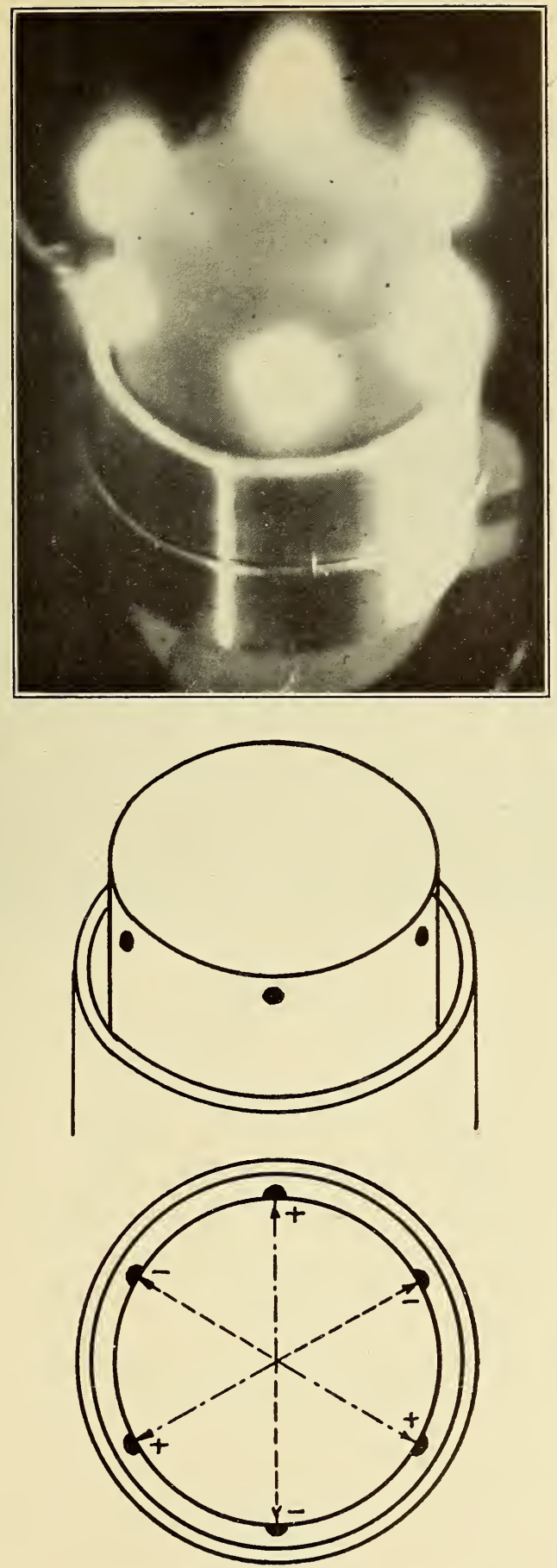

Figure 12.-331 kc, mounting B, height 36.67 $\mathrm{mm}$, diameter $24.715 \mathrm{~mm}$ 
B. S. Journal of Research, RP156
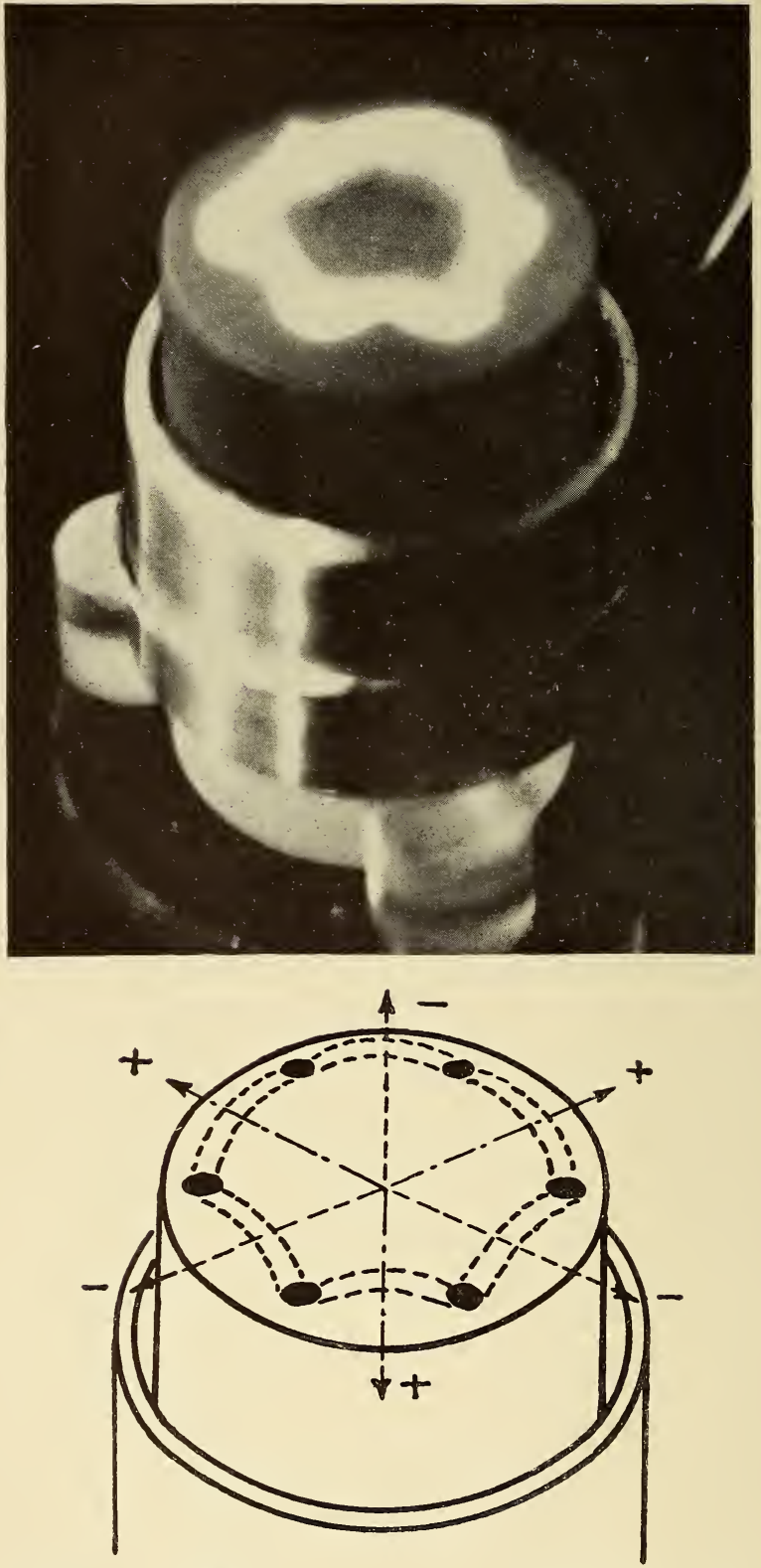

FIGURE 13.-296 $k c$, mounting $B$, height $36.67 \mathrm{~mm}$, diameter, $24.715 \mathrm{~mm}$ 
B. S. Journal of Research, RPI56
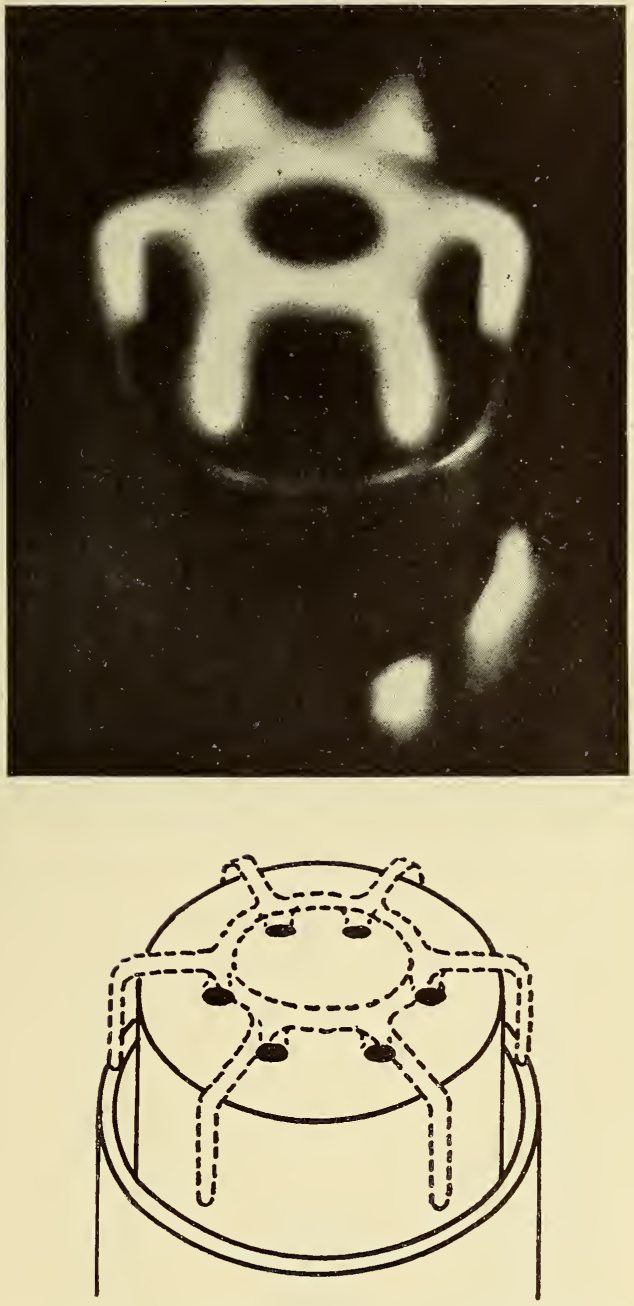

Figure 14.-262 kc, mounting B, height 36.6r $\mathrm{mm}$, diameter $24.715 \mathrm{~mm}$ 
B. S. Journal of Research, RP156
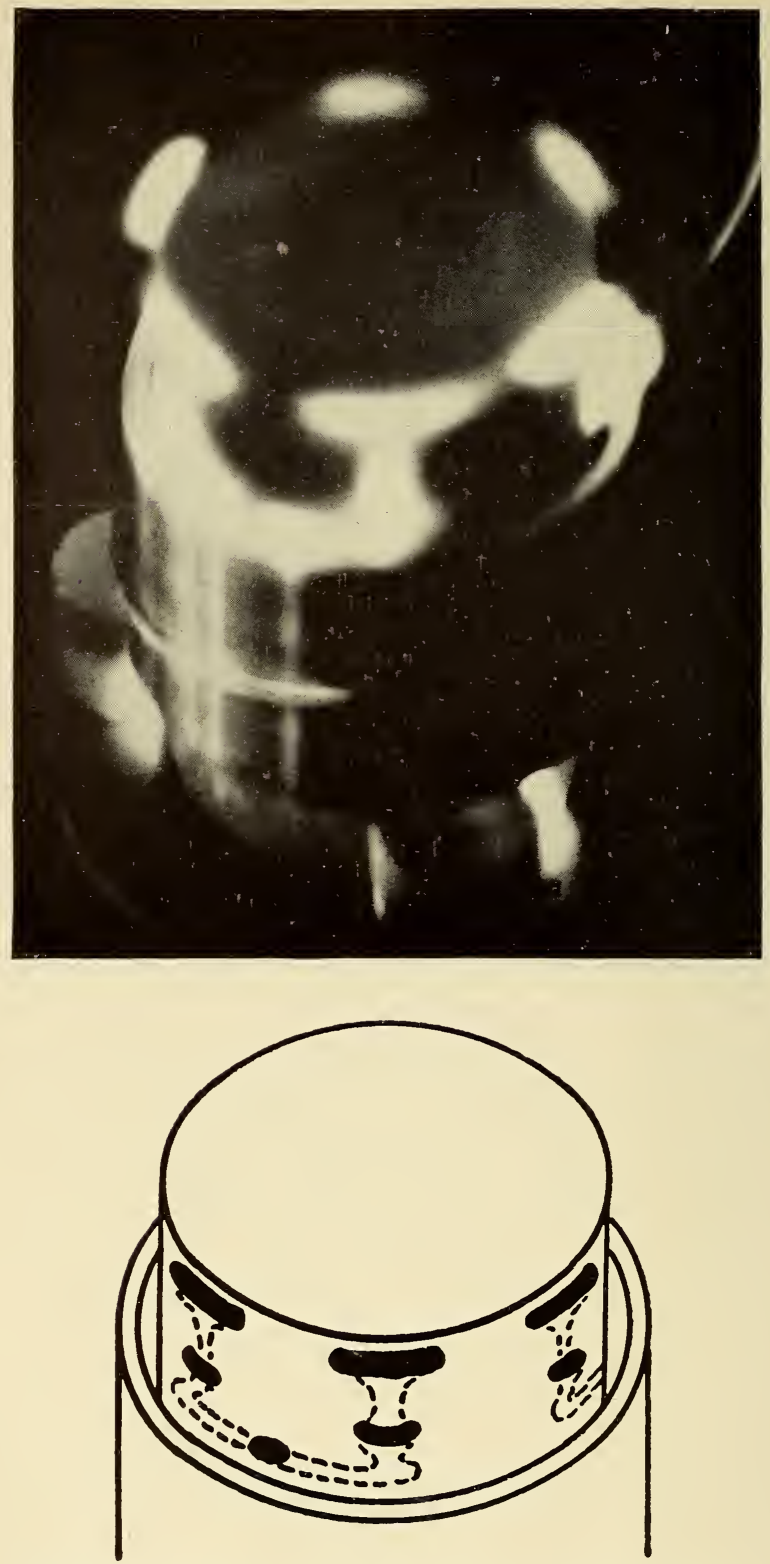

Figure 15.-174 kc, mounting $B$, height $36.67 \mathrm{~mm}$, diameter $24.715 \mathrm{~mm}$ 


\section{B. S. Journal of Research, RP156}
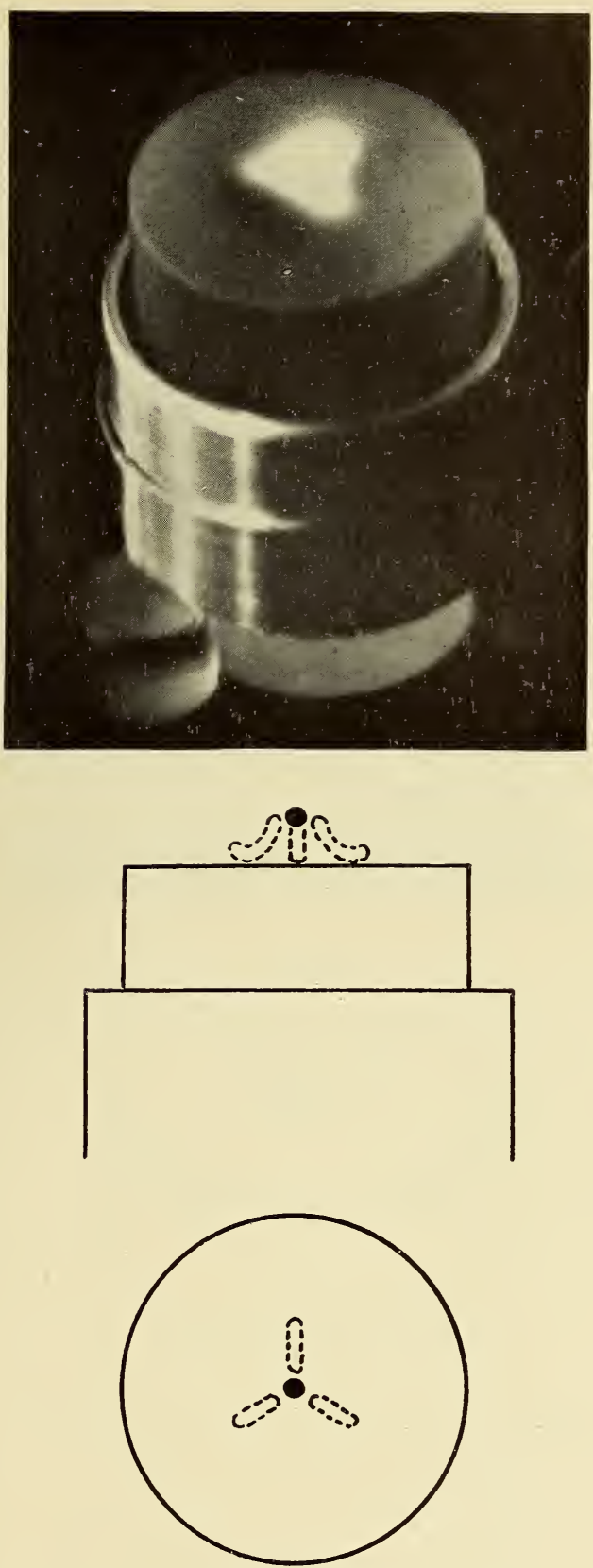

Figure 16.-186 kc, mounting B, height 36.67 $\mathrm{mm}$, diameter $24.715 \mathrm{~mm}$ 


\section{B. S. Journal of Research, RP156}
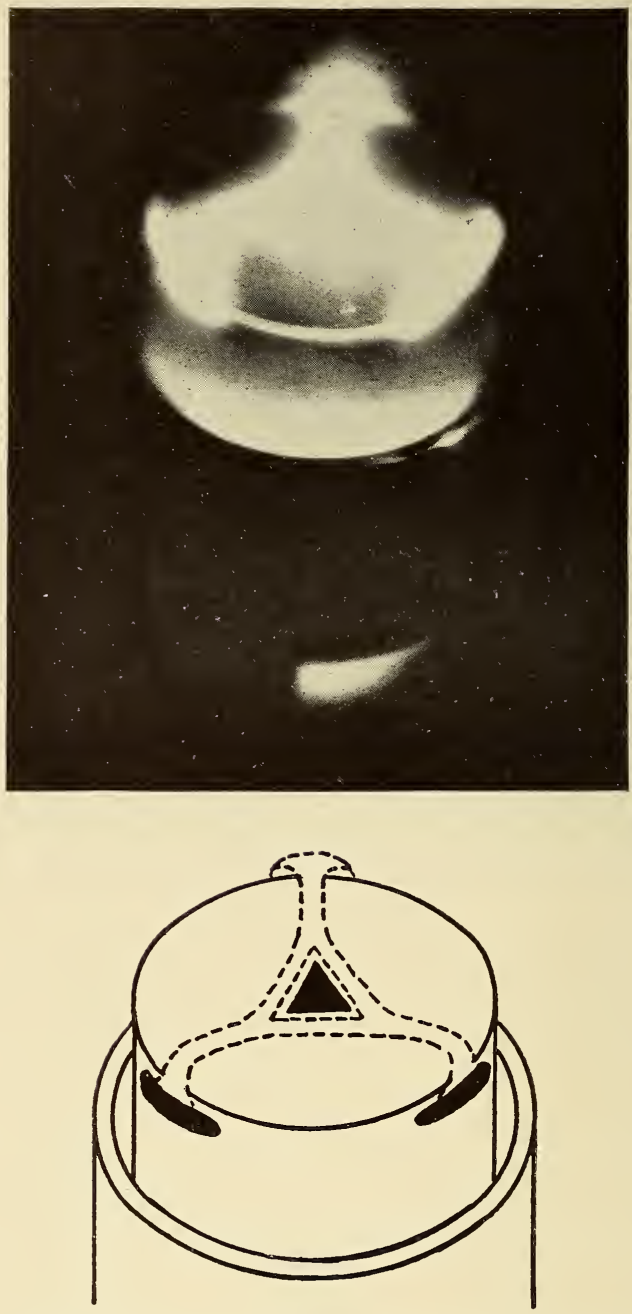

Figure 17.-1\%4-179 kc, mounting $B$, height $36.67 \mathrm{~mm}$, diameter $24.715 \mathrm{~mm}$ 

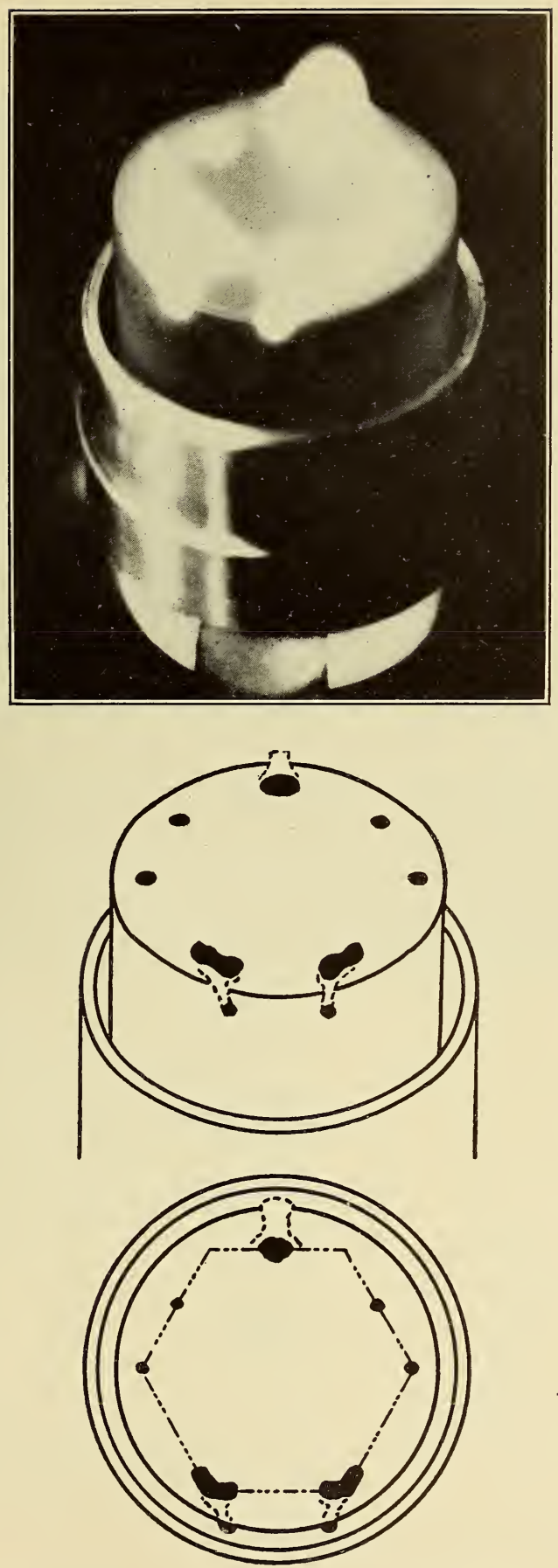

Figure 18.-440 kc, mounting $B$, height 36.67 $\mathrm{mm}$, diameter $24.715 \mathrm{~mm}$ 

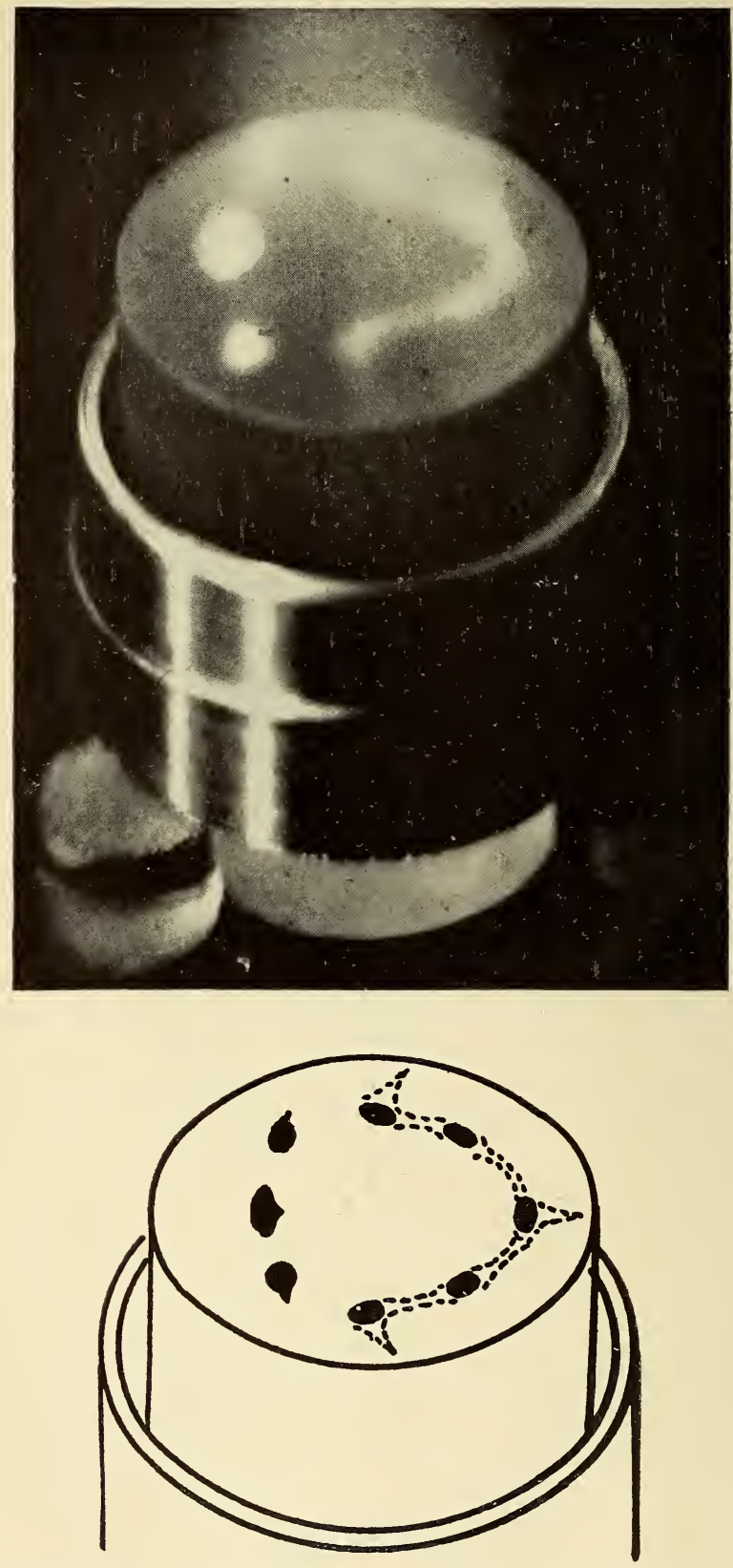

Figure 19.-520 kc, mounting $B$, height $36.67 \mathrm{~mm}$, diameter $24.715 \mathrm{~mm}$ 


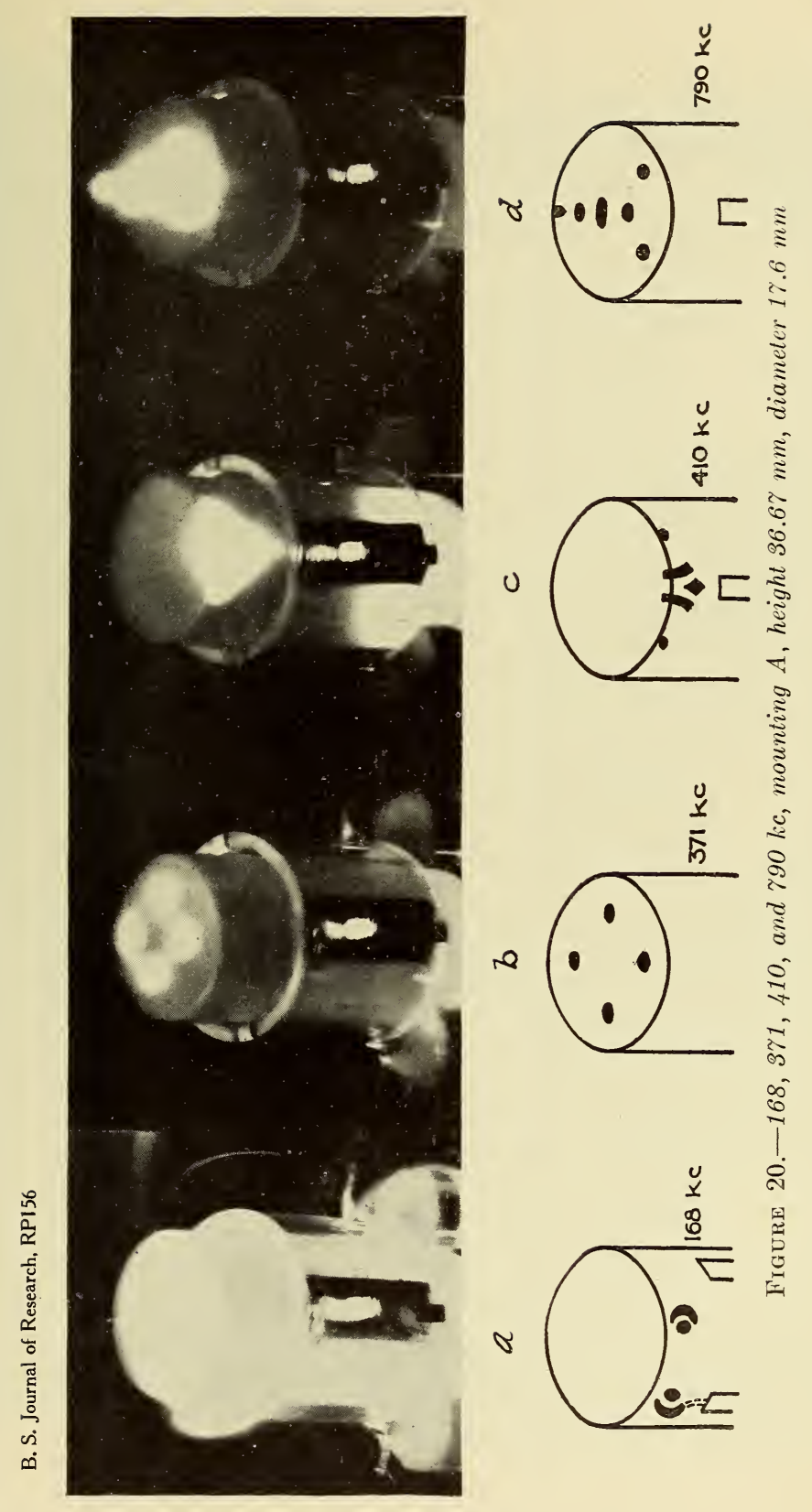




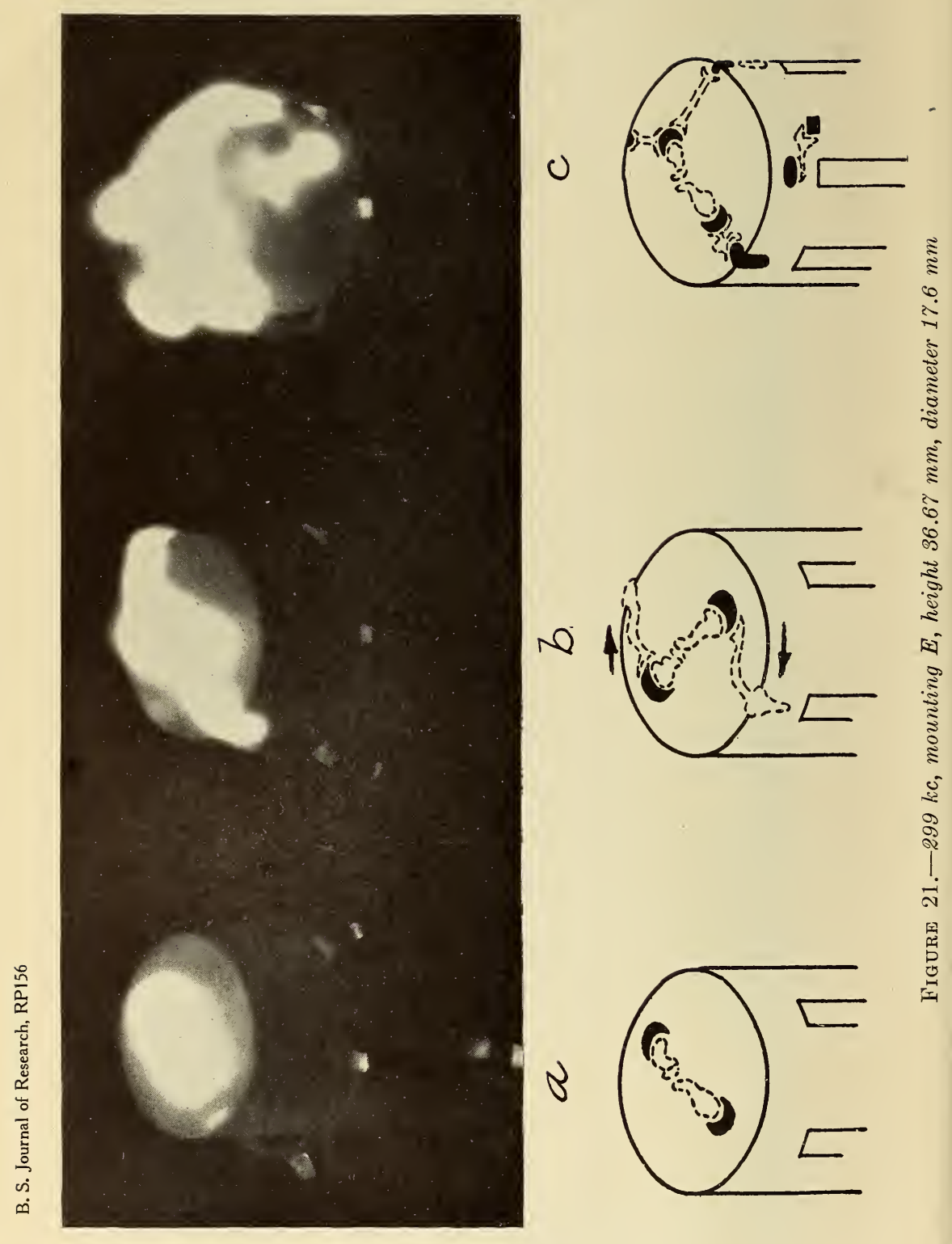




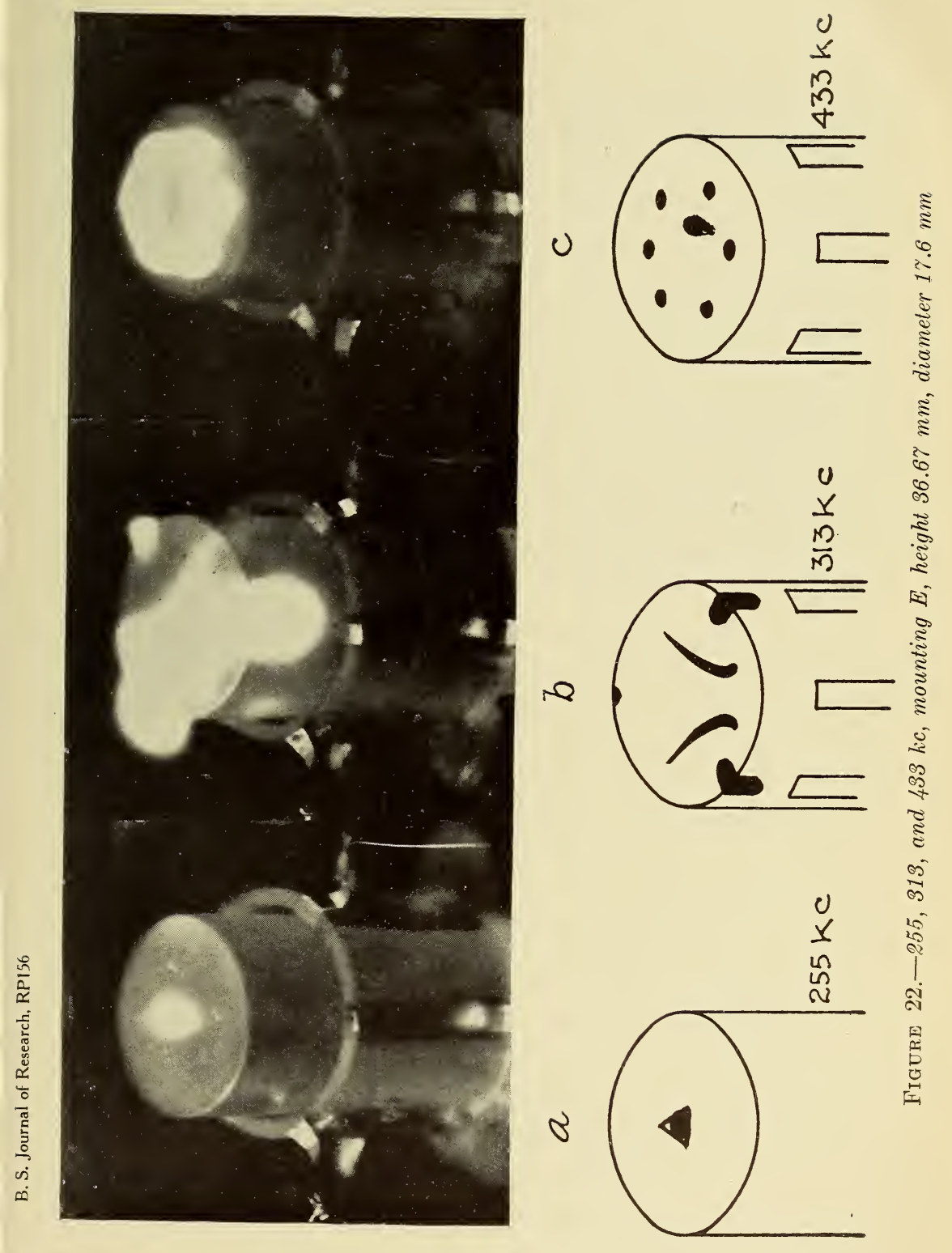



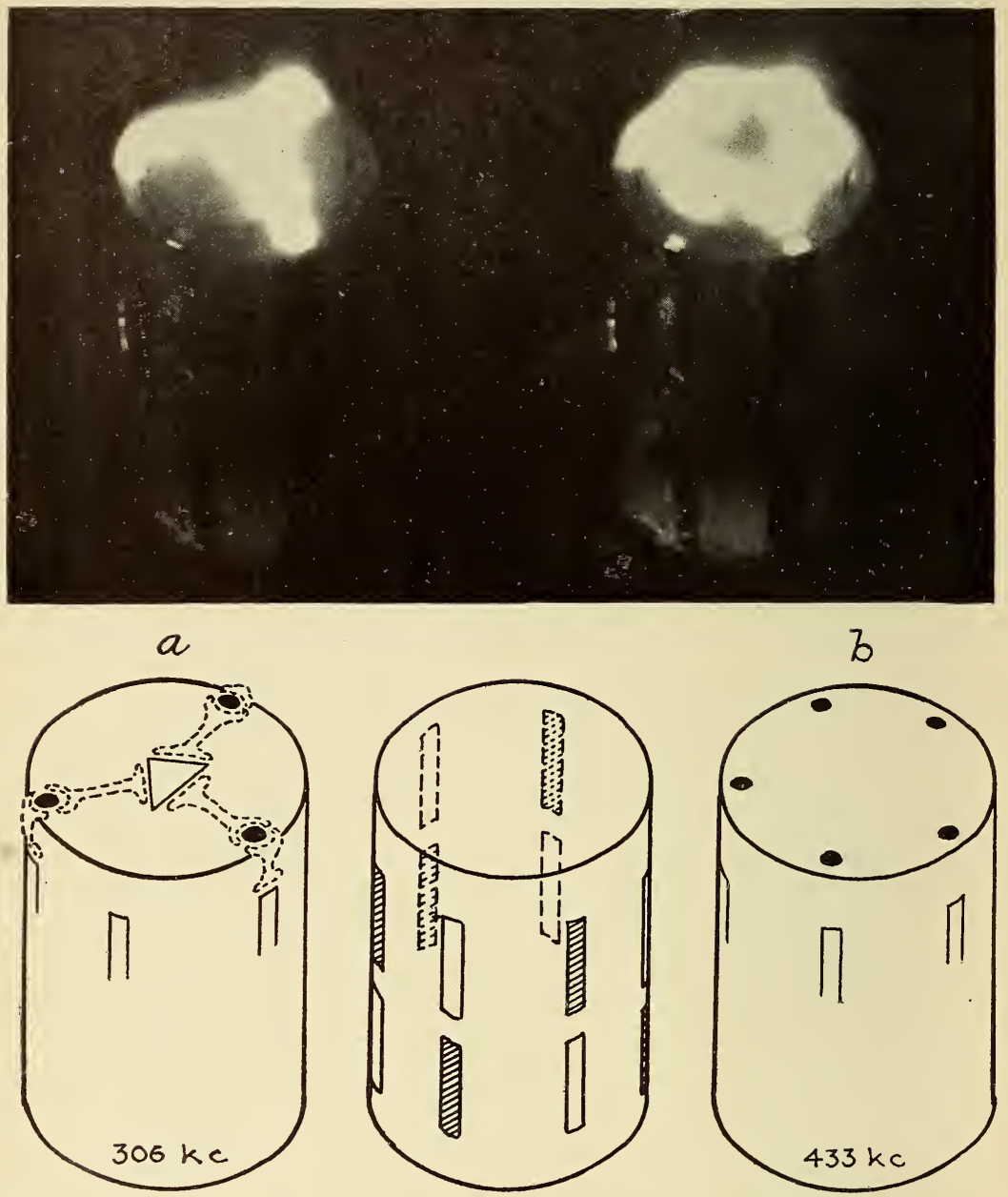

MOUNTING G. ALL SHADED ELECTRODES CONNECTED TOGETHER, AS ARE SHADED ONES.

Figure 23.-306 and $433 \mathrm{kc}$, mounting $G$ height $36.67 \mathrm{~mm}$, diameter $17.6 \mathrm{~mm}$ 
Figure 15 shows a display which accompanied the $174 \mathrm{kc}$ oscilla. tion, and Figure 16 that for the 186 kc oscillation, which latter consisted of a space charge globule elevated somewhat above the center of the top face and resting, so to speak, on its own discharge, which emanated from it in a downward direction, in the form of a tripod.

In Figure 17 is depicted a beat phenomenon between the two frequencies at which the cylinder was being simultaneously oscillated. On going up to still higher frequencies, the $440 \mathrm{kc}$ oscillation shown in Figure 18 was found. It consists of large and small discharge spots. Except for the three envelope discharge points these were found to lie on the indicated hexagon. The three large discharge points did not form an equilateral triangle in this case, but this may conceivably happen for higher modes of vibration.

For the 520 kc oscillation, the pattern of Figure 19 was obtained. Here four of the seven spots appeared to lie on a parabola.

\section{EXPERIMENTS WITH MOUNTINGS A, E, AND G}

It seemed of particular interest to find out whether oscillations could be produced using mounting A, with its four quadrant electrodes, considering the peculiar relation of the electrode system to the three piezo-electric axes. Oscillations were nevertheless obtained, as is shown in Figure 20. The electrode system in this case consisted of thin aluminum strips pasted inside of a glass cylinder whose inside diameter exceeded the diameter of the quartz cylinder by about 2
$\mathrm{~mm}$.

The $168 \mathrm{kc}$ oscillation, obtained with mounting A, consisted of a glow discharge in the upper left corner, coexistant with a similar one, diagonally opposite; that is, on that portion of the lower edge which can not be seen in the photograph. The diagonal effect for the 410 kc oscillation of Figure $20(c)$, however, can be recognized at least by the general glow to be seen through the lower portion of the cylinder. The $371 \mathrm{kc}$ oscillation produced four surface discharges on top of the

crystal, and the $790 \mathrm{kc}$ oscillation the pattern of Figure $20(\bar{d})$.
With mounting $\mathrm{E}$, which would appear to be a most natural one, embodying six electrodes placed around the cylinder, oscillations shown in Figures 21 and 22 were produced. Such a mounting may be placed in two distinctly different positions. It may be so placed that the electrodes cover either the points of maximum or the points of minimum piezo-electric polarization; that is, so placed that they former position may well be called the "Curie" or $0^{\circ}$ mounting, and the latter the $30^{\circ}$ mounting. Both mountings were tried, and oscillations were produced in each case. Whenever the same patternthat is, the same oscillation-was obtained in each case, it was found that the pattern occurred at the same position on the crystal irrespective of the mounting position. Thus, in the six glow discharge pattern of the $433 \mathrm{kc}$ oscillation shown in Figure $22(\mathrm{c})$, the six surface discharges occurred halfway between the actual piezo-electric axes for both the $0^{\circ}$ and $30^{\circ}$ mounting. At this point it may be of interest to recall the pattern of Figure 13 where, also, six circular discharges were obtained on the top face, but this with the cylinder drive $B$. In that case the discharges were also halfway between the piezoelectric axes. Moreover, referring again to mounting $\mathrm{E}$, it seems that with the $30^{\circ}$ location of the electrodes, oscillations may be 
brought in somewhat more easily, just as in ordinary piezo-electric work somewhat better response is obtained with $30^{\circ}$ cuts than with "Curie cuts."

The $299 \mathrm{kc}$ oscillation shown in Figure 21 can give patterns as indicated, depending upon gas pressure and feed back. The pattern in Figure $21(b)$ consisted of two surface discharges interlinked by a discharge which was raised above the surface of the crystal. The position of these surface discharges, with respect to the piezo-electric axes, depends apparently upon phase relationship. When the small condenser $\mathrm{C}_{1}$, or the regeneration control $\mathrm{C}_{0}$, of circuit, Figure $2(a)$, was changed by a small amount, this "doublet" turned around either by $60^{\circ}$ or by $30^{\circ}$. For the former case, the "doublet" swung into the adjacent piezo-electric axis and, for the latter, into a $30^{\circ}$ location. Since this took place without a frequency change it must have been caused by a change in phase.

The mounting G shown in Figure 23, was designed with the purpose in mind of producing torsional effects. All shaded electrodes lead to one terminal, and the remaining electrodes to the other terminal. From the discharge patterns and frequencies of oscillations obtained with this drive we must infer that the oscillations, in many cases at least, are the same as obtained with mountings B, C, D, E, and F. An interesting point about this drive is that the orders of the modes of oscillation it produces are generally found to lie in a higher range than those produced with the other mountings.

\section{COMPARISON OF THE EXPERIMENTAL RESULTS}

Most of the patterns shown herein, and most of those observed by the authors but not shown, strongly indicate that the vibrations of the quartz cylinder are dependent upon piezo-electricity, since the patterns indicate either directly or, at least, suggest in a partial way, the piezo-electric structure. Tawil's "strepho-electricity" must be, therefore, a case of true piezo-electricity. This dependency of vibrations upon piezo-electricity may be better understood from a study of the electric lines of force involved. Consider, for instance, mounting B, which suggested itself from Tawil's experiments. The lines of force leave the end face electrodes parallel to the optical ( $Z$-axis, according to Voigt's notation) axis at first, then bend around, and finally enter the cylindrical electrode perpendicularly. Hence, there must be components along the three piezo-electric axes, which lie in the equatorial plane. These components must produce "Curie effects." In Table 1 are compiled some of the frequencies obtained either with the cylinder under a low pressure of helium gas, or in air, at atmospheric pressure. With the exception of those for mounting $A$, the discharge figures and the frequencies check each other more or less closely. The only frequency for mounting A which agreed with that for any of the other mountings was $433 \mathrm{kc}$. The pattern for mountings B, E, F, and $\mathrm{G}$ at this frequency, was that shown in Figure $22(c)$, six surface charges located halfway between the piezo-electric axes. But the pattern found at this frequency, using mounting $\mathrm{A}$, was somewhat different. It resembled a "doublet," very similar to the one shown in Figure $21(b)$, but smaller and excentrically located, on the top face of the cylinder. 
TABLE 1.-Oscillation frequencies in $k c / s e c$.

\begin{tabular}{|c|c|c|c|c|c|}
\hline $\begin{array}{l}\text { Mount- } \\
\text { ing A, } 4 \\
\text { electrodes }\end{array}$ & $\begin{array}{c}\text { Mount- } \\
\text { ing B, } \\
\text { cylinder } \\
\text { mounting }\end{array}$ & $\begin{array}{l}\text { Mount- } \\
\text { ing E, } 6 \\
\text { electrodes }\end{array}$ & $\begin{array}{l}\text { Mount- } \\
\text { ing } \mathrm{F}, 3 \\
\text { rings }\end{array}$ & $\begin{array}{c}\text { Mount- } \\
\text { ing G, 12 } \\
\text { electrodes }\end{array}$ & Remarks \\
\hline \begin{tabular}{|c|}
125 \\
203 \\
215 \\
257 \\
267 \\
371 \\
383 \\
410 \\
433 \\
470 \\
475 \\
\end{tabular} & $\begin{array}{l}395 \\
417 \\
433 \\
446 \\
489 \\
600 \\
\end{array}$ & \begin{tabular}{|c}
240 \\
255 \\
289 \\
313 \\
380 \\
395 \\
417 \\
433 \\
\\
\\
\end{tabular} & $\begin{array}{c}417 \\
545 \\
\\
\end{array}$ & \begin{tabular}{|c|}
168 \\
\\
\\
\\
\\
\end{tabular} & $\begin{array}{l}\text { With mounting F, crystal was driven } \\
\text { in air. With all others, crystal was } \\
\text { driven in a low pressure of helium. } \\
\text { Height of cylinder } 36.67 \mathrm{~mm} \text {.; diam- } \\
\text { eter, } 17.6 \mathrm{~mm} \text {. }\end{array}$ \\
\hline
\end{tabular}

With some mountings the phenomenon of recurring patterns was observed. With both mountings B and G, both the 433 and $446 \mathrm{kc}$ oscillations produced the same 6-spot pattern (fig. 22 (c)) mentioned above. Similarly, with mounting $\mathrm{B}$ both the 251 and $255 \mathrm{kc}$ oscillations produced the same triangular spot (shown in fig. $22(a)$ ) at the center of the top face.

\section{THEORETICAL CONSIDERATIONS}

In general, there are three fundamental modes of possible natural oscillation, each of a different nature, as well as the modes of higher order for each of the three, which must be considered. Even in the relatively simple case of an isotropic substance we find that the formulas for vibrations of a body may involve three velocities of propagation, $v_{1}, v_{2}$, and $v_{3}$. The first two of these are due to the fact that we have a linear modulus of elasticity, $E_{1}$, and a torsional modulus, $E_{2}$, to deal with in case of longitudinal and torsional vibrations, respectively. The third velocity is due to what we may consider as a corresponding $E_{3}$ effective in the case of transverse vibrations. Thus if $D$ denotes the density, which is $2.65 \mathrm{~g} / \mathrm{cc}$ for crystal quartz:

$$
\begin{aligned}
& v_{1}{ }^{2}=E_{1} D^{-1} \\
& v_{2}{ }^{2}=E_{2} D^{-1} \\
& v_{3}{ }^{2}=E_{3} D^{-1}
\end{aligned}
$$

However, $E_{3}$ should not be considered as independent; a simple relation is found to exist between $E_{1}$ and $E_{3}$ such that we may con- 
veniently write for the corresponding frequencies, $f$, of vibration in the case of a cylindrical body:

$$
\begin{aligned}
& \text { (longitudinal) } \quad f_{\text {long }}=\frac{p}{2 l} \sqrt{\frac{E_{1}}{D}} \\
& \text { (torsional) } \quad f_{\text {tors }}=\frac{p}{2 l} \sqrt{\frac{E_{2}}{D}} \\
& \text { (transverse) } \quad f_{\text {trans }}=\frac{d \psi_{p}^{2}}{8 \pi l^{2}} \sqrt{\frac{E_{1}}{D}}
\end{aligned}
$$

where $p$ stands for the order of the mode ( $p=1$ for the fundamental) and $d$ and $l$ denote the diameter and height of the cylinder, respectively. The values of $\psi_{p}$ for the fundamental, and some of its higher modes, are:

$$
\begin{aligned}
& \psi_{1}=4.71 \\
& \psi_{2}=7.85 \\
& \psi_{3}=11.0 \\
& \psi_{4}=14.1 \\
& \psi_{5}=17.3
\end{aligned}
$$

From this it can be seen that for a cylinder, only the transverse modes of oscillation are affected by the size of its cross section, that is, by its diameter. This is true, however, only when the cylinder height is large compared with the diameter.

The above formulas are all well known. Moreover, it is evident that those for torsional and transverse vibrations may be rather conveniently expressed in terms of that for longitudinal vibrations. Thus we may write:

$$
f_{\text {tors }}=\frac{f_{\text {long }}}{\sqrt{2(1+\mu)}}
$$

Where $\mu$ may have values between 0.2 and 0.5 depending upon the values of $E_{1}$ and $E_{2}$. And for the transverse frequency we obtain:

$$
f_{\text {trans }}=\frac{\pi(2 p+1)^{2}}{16 p} \cdot \frac{d}{l} f_{\text {long }}
$$

from which, for the fundamental mode:

$$
\left.f_{\text {trans }}\right|_{p=1}=1.767 \frac{d}{l} f_{\text {long }}
$$

These formulas will give, of course, no very reliable values for crystalline quartz since the modulus of elasticity, although constant in the equatorial plane (perpendicular to the optical axis), is different for all other directions. Fortunately, however, earlier experimenters in the field ${ }^{8}$ have determined the longitudinal modulus $E_{1}$, as well as the torsional modulus $E_{2}$, along the optical axis. They are:

$$
\begin{aligned}
& E_{1}=10.304 \times 10^{11} \\
& E_{2}=5.085 \times 10^{11}
\end{aligned}
$$

${ }^{8}$ Voigt, Riecke, Pockels, and others. 
The values under the radicals in (2) represent velocities, as may be seen by referring to (1), and become, with the above values of elasticity, and the density given previously:

$$
\begin{aligned}
& v_{1}=6.24 \times 10^{5} \mathrm{~cm} / \mathrm{sec} . \\
& v_{2}=4.38 \times 10^{5} \mathrm{~cm} / \mathrm{sec} .
\end{aligned}
$$

For the longitudinal and torsional modes of oscillation of a cylinder of crystalline quartz cut along the optical axis, therefore, we have:

$$
\left.\begin{array}{rl}
f_{\text {long }} & =\frac{312 p}{l} \\
f_{\text {tors }} & =\frac{219 p}{l}
\end{array}\right\} \text { kilocycles/sec. }
$$

where the length, $l$, of the cylinder is expressed in centimeters and $p$ stands for $1,2,3,4$, etc., according to the order of the mode.

For the transverse modes the expression in (2), together with the above value of $v_{1}$, gives:

$$
f_{\text {trans }}=24.8 \frac{d \psi_{p}^{2}}{l^{2}} \text { kilocycles } / \text { sec. }
$$

where both the length, $l$, and the diameter, $d$, of the cylinder are expressed in centimeters. As far as the fundamental of this transverse mode is concerned (5) and (6) check (7) for the value of $\psi_{p}=4.71$, and lead to:

$$
\left.f_{\text {trans }}\right|_{p=1}=550 \times \frac{d}{l^{2}}
$$

Of course, formula (7) must be considered as an approximation because of the lateral effect. But it should give values sufficiently close to warrant the speculation undertaken in Table 2. In this table are compiled for comparison calculated and experimental values of frequency (for the larger diameter crystal, $d=2.4715 \mathrm{~cm}$ ). It appears that most of the torsional oscillations were obtained, including the fundamental, which has hitherto not been mentioned. No description of the pattern for this fundamental mode is given because the oscillation could be produced only in air, at atmospheric pressure, the reason for which would no doubt be found in a study of the characteristics of the particular drive used.

$T_{A B L E}$ 2.-Theoretical and experimental frequencies for cylinder, in kc/sec.

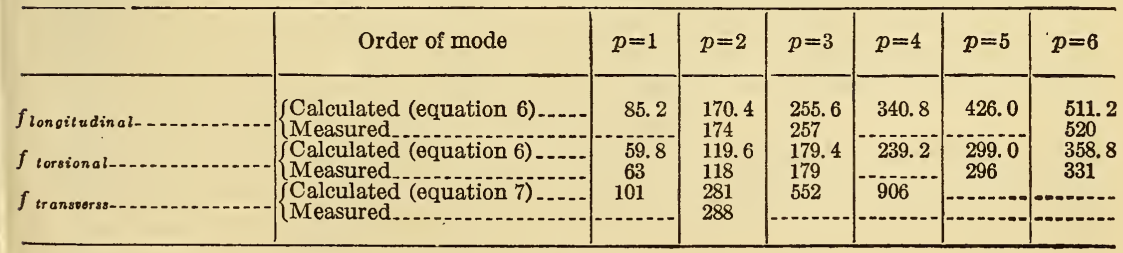

Length, $l=3.667 \mathrm{~cm}$; diameter, $d=2.4715 \mathrm{~cm} ; d / l^{2}=0.184$. 
It is interesting to note that for the cylinder of smaller diameter $(d=1.76 \mathrm{~cm})$, but of the same length there was found a frequency corresponding exactly to one appearing in Table 2 , namely, $118 \mathrm{kc}$. This indicates that for this particular mode and order at least the frequency is independent of cross section.

\section{CONCLUSION}

Although there are reasons why the comparison in Table 2 is of a speculative nature, nevertheless, after examining it, it is very difficult to believe that all the oscillations are of the same mode even if they were all obtained using the same mounting $\mathrm{B}$ and drive $a$. The table seems to indicate, however, that torsional oscillations predominate with this combination of mounting and drive.

As was pointed out in the description of the patterns shown, in most cases the hexagonal formation was' indicated, and in many cases the actual piezo-electric axes were either marked out by discharge points or indicated by points midway between. A pertinent point in this respect, and also in its relation to Tawil's work, is that the frequencies of two of the most striking examples of this indication of piezo-electric axes appear to correspond, as shown in Table 2, with torsional vibrations. In Table 1 is to be found a second interesting fact in this respect. It is that most of the frequencies produced using the ring mounting (mounting $B$ ) can also be produced using the 6 and 12 electrode drives (mountings $\mathrm{E}$ and $\mathrm{G}$, respectively).

In general, the observed facts of these oscillations seem to be in perfect harmony with the previously known phenomena of piezoelectricity; no need for other explanations appears.

Washington, September 3, 1929. 